\title{
Emotions and embodiment as feminist practice in the free abortion movement in France (1972-1984)
}

\section{Lucile Ruault}

Cermes3 (CNRS/Inserm/EHESS/Paris Descartes) and CERAPS (CNRS/University of Lille), France

\begin{abstract}
This article explores the critical role of emotions and bodies in the individual dynamics of engagement as well as the construction of collective identities and action in women's groups in the 1970s in France. Much literature on emotion work in feminist organizations has tended to discuss emotions stemming from women's dominant socialization processes as, above all, alienating, thereby as barriers to their activism. The Movement for the liberty of abortion and birth control offers essential insights into how gendered dispositions can be primary determinants of feminist collective identity formation, and even spur innovative protest practices. With their specific organizational settings and action, some 'dissident MLACs' in Aix-en-Provence, Lille, Lyon and Paris - those which continued to practice abortion despite its legalization and in defiance of the 1975 law which forbade them to do so-mobilized reciprocal emotions and bodily experiences to sustain engagement and serve a political project. Drawing on a wide array of biographical interviews and archival sources centred on abortion practices, the article examines the distinctive emotion culture these groups constructed. Its anchoring in bodies, commitment to emotions like tenderness and compassion, but also domestic and relational skills consecrated a gendered repertoire of action which therefore notably appealed to women whose social properties did not predispose them to collectiveaction.
\end{abstract}

\begin{abstract}
'Something emerged from it, a fight that is about oneself, where one really engages with one's own body and so, yeah, with others'. These words used by Annick, a former activist in the Movement for the Liberty of Abortion and Birth Control (MLAC; Mouvement pour la liberté de l'avortement et de la contraception) in France in the 1970s, encapsulate the centrality of embodiment and its deep entanglement with emotion work (Hochschild, 1979) in the practices of activists fighting for free abortion at the time. This article proposes to explore this connection between body and emotions in more depth, using the case study of this social movement oriented towards 'direct action' which promoted the practice of abortions before and after abortion was made legal in France.
\end{abstract}

Starting in 1973 as a largely decentralized movement, the MLAC was a network of roughly 250 groups (in the large- and medium-sized cities of metropolitan France) and attracted heterogeneous activists among leftist, feminist and trade union post-1968 networks (Bateman-Novaes, 1979; Pavard, 2012; Zancarini-Fournel, 2003). Some MLACs used direct action, engaging in the practice of illegal abortions, directly opposing the State and its laws, as well as (male) medical experts' monopoly over the practice, after it was finally made legal in 1975. While a dividing line emerged early on between physician-led MLAC groups and those led by lay activists, they still shared an interest in going beyond service provision to contribute to consciousness-raising among aborting women. MLAC organizers were more or less successful in coupling their double goals of helping women in need of an abortion and stimulating their political empowerment. While 'voluntary terminations of pregnancy' became legal exclusively in officially recognized medical institutions - that is, by state and private clinics - in 1975, four MLAC groups continued to perform home-run abortions in Paris (until 
1980), Aix-en-Provence ${ }^{1}$, Lille and Lyon (until 1983-1984) in defiance of the law. In doing so, they differentiated themselves from most other MLACs which disappeared or reoriented their action by focusing on the application of the law. Beyond helping women who were marginalized by the legal framework, such as minors who still had to show consent from their guardian to be granted abortion, these 'dissident' groups claimed that issues of procreation should not be confined to medical institutions. Laywomen from these MLACs, who were trained in vacuum aspiration by a few activist doctors in 1973, gradually innovated until they developed their own abortion procedure. Beyond the practice of abortion, they strived to address the broader dynamics of women's agency towards their bodies and their daily lives, regarding the patriarchal control exerted by their husbands and fathers, but also by doctors, judges and politicians. While opting for a type of illegal activism by performing home-based abortions, and despite a new context that constrained their resources and their relationships with other MLACs and the women's movement, these organizations lingered on and renewed their membership.

In this article, I propose to elucidate the paradox by which marginal groups engaged in an illegal abortion practice managed to persist and to recruit members even after abortion had become accessible in hospitals after 1975. I investigate this paradox empirically by examining the distinctive emotion culture (Hochschild, 1990; Taylor, 1996, 2000) they constructed, thus further illuminating how emotions matter for the functioning of feminist organizations in periods of abeyance (Taylor and Whittier, 1992; Whittier, 1995). While underlining the centrality of gendered dispositions towards certain emotions and care practices, I argue movement that 'reciprocal emotions' (Jasper, 1998) and bodily experiences were crucial in both the individual processes of engagement in the groups and in the formation of collective feminist identities.

This article draws on 60 life narratives of activists and the unclassified archives of four dissident MLACs (Ruault, 2017). The interviewees were White women², who were 14 to 41 years old when they first became involved in the MLACs; they all identified as heterosexual. Their professional activities ranged from cleaners to senior executives, industrial workers to teachers - within some cities a slight over-representation of teachers or educators. The Aix-MLAC archives contained records of 1520 abortions for which women left information and comments (personal data, details about previous pregnancies, abortion proceedings and their sequels, etc.). These archives provide exceptional insights into the viewpoints and emotions of women who experienced an abortion with the MLAC at the time. I also relied on 10 interviews with women who first had an abortion in one of the four dissident MLACs; most of them subsequently became activists.

Drawing on this rich sets of data, this article explores how emotions and a specific emotional culture created by these groups helped to transform 'users', or women who came to have an abortion, into activists, thereby ensuring the persistence of these groups for several years after the legalization of abortion in 1975. I begin by briefly situating my analysis within the literature about emotions and feminist organizations. Then I provide an overview of women's motivations to participate in the MLACs, and the significance of bodily and emotional dimensions in the processes of becoming an activist. Finally, I examine the intense sensory culture these groups cultivated, to discuss the gendered appropriations of repertoires of collective action. 


\section{Utilizing instead of transforming gendered emotions}

Contesting the limiting dualism between rationality and emotions that used to underpin much literature on social movement (Ferree, 1992; Taylor, 1995), some feminist scholars have explored the role of emotional framing in strategic and organizational dynamics in the women's movements. They analysed how organizations manage feelings in relation to external actors (Coe and Schnabel, 2011; Gould, 2002), as well as internal work (Guenther, 2009; Reger, 2004; Taylor, 1996). The legitimization of the expression of anger is paradigmatic of this process (Flam, 2005; Hercus, 1999); its appropriation by powerless people means reversing dominant emotions tied to femininity, shaping 'deviant' emotions conducive to protest and redirecting them towards opponents. When scholars examine 'gendered outlaw emotions' (Reger, 2004: 212) that bring women into organizations, when they analyse the transformation of women's emotions deemed paralysing, or when they focus on the production of empowering emotions such as anger, they tend to emphasize newness and the redefinition of feelings as prerequisites for protest, thus neglecting the role of previously acquired gendered modes of expression. This emphasis on 'emotional liberation' (Flam, 2005: 31) frames emotions stemming from gendered socialization processes as above all alienating, and therefore to be overcome. This body of literature thus rests on the tacit assumption that gender norms are a meagre resource for feminist activism, even a limit, which leaves unresolved the issue of how ordinary women may ever mobilize and become feminists. Dissident MLACs offer essential insights into how emotional gendered dispositions can be at the root of feminist collective identity formation and spur innovative protest practices.

Building upon research on communities which promote women bonding, the analysis presented here extends their findings by enhancing bodily experiences in the creation of solidarity. Indeed, when examining the 'ethic of care' promoted by feminist organizations (Guenther, 2009), even in 'therapeutic' contexts like the postpartum depression movement (Taylor, 1996), scholars rarely explore how the production of affection, mutual trust, caring and emotional ties is embodied. More often, they examine how 'shared emotions are created through cognitive processes' (Reger, 2004: 214). Although bodies mediate feelings, they frequently vanish in the analysis of the emotional dynamics of feminist practices. The study of 'dissident MLACs' opens the door to analysing how women's organizations can mobilize emotions and bodily practices to sustain engagement and serve a political project. Digging into 'how emotional framing is actually achieved' (Hercus, 1999: 36), this article broadens our analysis of how bodily factors influence the participation in feminist movements and social movements more largely (Brown et al., 2004).

Drawing on Michelle Murphy's (2012) work on feminist self-help protocols, I will examine the emotional logic of activist practices that pursued the 'elevation of experience and sensation' (p. 76) as the primary tools for awareness, creation of knowledge and learning. I analyse embodied care practices referring to the guiding epistemic values Murphy (2012) highlights, 'using your body to know your body, valuing and producing affirmative affective relations, appreciating variability, and collective research' (p.73). 


\section{Abortion activism: A pathway to feminism through practice}

Dissident MLACs are stimulating sites for observing how 'ordinary' women were socialized into politics in the 1970s, a context of 'capillary diffusion of feminist ideas' (Achin and Naudier, 2010: 79). These groups simultaneously revealed to women structural interpretations of their lived realities of domination and opened up a certain understanding of politics.

For almost half of the ordinary (i.e. non-physician) women interviewed, participation in a MLAC group was the only form of political activism they engaged in. They often presented themselves as 'not politicized', sometimes even disavowing having been an 'activist', and they did not display the usual social profile found in the feminist movement of the time: upper-middle-class occupations, as executives and in intellectual professions as well as in higher education (Masclet, 2017: 310-313). MLAC groups brought together a great diversity of profiles, social resources, lifestyles and trajectories.

The variety in this social make-up suggests that these MLACs were conducive to the involvement of women from less educated backgrounds and often those politically inexperienced. Given the unequal (feeling of) political competence between the MLACs' members, what processes jointly led them to feminism? While attempting to elucidate the dynamics of feminist participation of both first-time activists and individuals with previous experience in leftist organizations, their convergence in dissident MLACs provides clues as to what underlies this protest project. While as in many feminist movements (Kesselman et al., 1998; Taylor, 2000; Taylor and Rupp, 1993), the development of women's sociability definitely played a role in motivating and sustaining activism within the MLACs, I emphasize here two factors less explored in the literature: the role of emotions and embodiment in the awareness of their shared preoccupations as women, and the anchor in experiential knowledge.

\section{'An obligation to other women' translated in bodily experiences}

When interviewees describe their motivations for participating in a MLAC's activities, the recurrent verb 'feel' underlines that political subjectivation largely occurred through emotional bodily states. However heterogeneous the pathways to MLAC activism were, their narratives show the importance of gendered ordeals in relation to sexuality, fertility regulation and procreation, which the interviewees knew intimately. Many interviewees claim to have reacted upon their emotions: chronic fear of pregnancy, shame or feelings of betrayal from experiences of maternity or abortion labelled as deviant ${ }^{3}$, violent childbirth, chauvinistic behaviour in sex, a sense of fate about multiple pregnancies and hardship in the women's lineage strengthened their impetus for change. The experience of abortion is obviously the first common denominator.

Even when experienced beforehand in a tragic way, abortion transmutes into a form of experiential knowledge mobilized in the context of activism. Hence, some interviewees significantly drew a dividing line between the women who joined the MLAC 'through politics' and those who entered through bodily experiences. Josette, an activist in AixMLAC, was born in 1939 in an Italian Catholic family in the sub-proletariat of Eastern France, where her father was a lumberjack. She moved to Provence at the age of 21 to escape family control and her destiny as a household servant. Soon after she married she 
endured exhausting domestic, sexual and reproductive exploitation: 'I had three children in three years. And then he made me abort eight times in four years' with an abortionist from a neighbouring village and then a clinic when bleeding started. 'That's why I got involved in the MLAC later. I had left too much of my body there'. This bodily experience could be used as a source of legitimacy in activism, as Mireille, an activist in Paris- $12^{\mathrm{e}}$ MLAC, later Place-des-Fêtes-MLAC, suggests, "they said, "I know what I have suffered". But myself, not having an abortion, I don't have that explanation'. Others emphasized recognition of the skills acquired by having experienced abortion(s). Four decades later, Irène (Paris-12 - MLAC) recounts her training in vacuum aspiration: 'Anna taught me how to practice [abortion]. Because I had had an abortion. It's true we do things intuitively, based on kinds of feelings. I was very scared, but I had some knowledge too'. In the context of MLAC activism, these women could therefore make claims using their own moral and physical experiences, framed as legitimate sources ofknowledge.

The stories collected from those who had an abortion in a MLAC group also insist on the 'duty to help' others. Josiane, a caseworker born in 1950 in a 'very inhibited family context', was confronted with pregnancy around the age of 26. At the hospital, a doctor patronized her 'so that [she] didn't have an abortion'. Rejecting any guilt, she 'slammed the door'. 'Stressed' by the progress of pregnancy, she happened to meet the MLAC's 'girls with their trestle tables' in a North Parisian market. She received an emotional boost from undergoing abortion with them:

Oh, I went out, I was completely euphoric! [ . . .] Realizing that for ten years I hadn't taken the pill for peanuts, and then that I didn't want this baby, it went without anyone making me feel guilty, it went off without a hitch, easy! At the same time, the conditions of the abortion were clean, well-managed, with humane, clever girls! Out of there, I remember walking the streets, like mad! I was thinking: [. . . that's so nice what's happening!

With her libertarian sensibility, Josiane had avoided any involvement in activist groups until then. Yet, she stayed for 3 years in the Place-des-Fêtes-MLAC. Her exhilarating experience of abortion only partly explained it:

I learned the practice from them. Since I had used it, I thought it was normal [. . .] [to] do it for others, and also to train others. [. . . I had a duty, but it isn't activist . . . . . . I It's a gift, I was given a gift. I give back what I was given. Because that's a transmission . . . It's not a religious transmission, not a political one, it's a transmission of relationship to one's body.

The 'transmission' embodied through this abortion made her feel the need to reproduce care for others. In fact, her desire to propagate such helpful 'relationship to one's body' meant both gratitude towards the group and empathy towards aborting women.

Insistence on moral dispositions is quite common in the interviews. The need to give a counter-gift also entailed the involvement of former activists, such as Jeanine (Placedes-Fêtes-MLAC), who grew up in a working-class family with nine children and after May '68 campaigned for the Maoist group Gauche Prolétarienne. In the spring of 1973, when she was pregnant, a MLAC was created in the 19th arrondissement of Paris. Contrasting with her painful abortion a few years before, when the hospital treated her as a 'social leper', her new abortion was enjoyable: 'To live this abortion collectively, in a completely different atmosphere, with kindness, solidarity . . . Then I found there was tenderness, love'. From her childhood characterized by silence about bodies, Jeanine had been torn about female corporeality - menstruation ('a horror!') as well as getting 
pregnant, which 'shouldn't have happened to me'. For her, 'the body was a kind of object of pleasure or displeasure. But nothing more'. This abortion, spoken about collectively, gave her access to a new emotional expressiveness towards her body:

I really had the opportunity to think about this pregnancy, there was freedom of speech. Then we tackled the whole question of sexuality and pleasure [. . .] Finally, I was taking over . . . my body. [. . .] There this body became another, I was finally living in serenity, and it opened up a very, very important space for me.

Jeanine's recollection pinpoints pivotal aspects of these MLACs' political work, namely 'the doctrine of validating women's experience' (Murphy, 2004: 140). As a result, this critical moment could raise women's awareness of their own bodily states and shared concerns. Just like for Josiane, self-care conditioned care for others, and that was crucial for keeping their commitment: 'insofar as it had happened that way for me, I owed something to women as well'. Jeanine felt morally obligated to bring to other women this feeling of empowerment over one's body. Abortions, as positive physical experiences, therefore created a framework of socialization, favouring emotional motivations oriented towards women's mutual support.

From the interviewees' accounts, abortions were both subjective and objective experiences, that is, shaped by a set of constraints (repression, social environment, institutional or activist intervention), through which the acquisition of knowledge socialized them to a 'joint procreative work'. Whether aborting implied physical violence (Josette) or, after 1973 and in the MLACs' context, positive outcomes (Josiane, Jeanine), bodies and emotions heightened their awareness of a responsibility to act for others. This connection is even truer of women who rejected any intellectualized relationship with politics. The embedding of activist work in physical biographies can be fully grasped in Josette's terms: 'Feminism? I don't think there's anyone who's more a woman than me! Because having suffered as I have, and all that I then tried to give, that's being a feminist'. While saying she is 'not politicized', her participation to the Aix-MLAC's collective identity was sustained by these emotions that she presents as rooted in her bodily experiences as a woman: since her sexuality, motherhood and abortions had been completely out of her control, the MLAC activated an awareness of women's experiences through the body, fuelling her profound empathy for other women.

\section{'A radicality rooted in practice'4}

Both interviews and MLACs' archives are loaded with the term practice, which has proved to be a means of mobilizing women for political action. For example, Odile insists that the Aix-MLAC exemplified 'a reality of practice, in the broadest sense: not only abortions, but also childbirth and IUD insertion. But a group practice'. First-time activists' comments support this analysis: they joined the movement because it appeared to them very different from other feminist organizations, from which they felt estranged. Edith (Aix-MLAC) recounts,

Friends told me about the MLF [Women's Liberation Movement]. But I was afraid [. . .] they were just brainy women who only blah blah. And then someone finally tells me about people who're doing real work, grassroots work. It was the MLAC. And that's when I joined les copines... 
The vacuity of abstract reasoning was a recurrent accusation against the activity of 'MLF feminists' and leftist organizations, unlike the MLACs' experience-based interpretations. The priority given to action was a precondition for Anne's involvement in Lille when she was 17 years and had dropped out of school: 'I didn't have a bookish approach at that time. [. . .] I preferred something very concrete, humane'. Similarly, Olga entered the Aix-MLAC at 19 years, after her abortion, because she felt this collective was 'involved in politics on a daily basis. It's not just grandiloquent waffle'.

Starting from experience also facilitated the stepping forward of interviewees from the educated middle-class who felt uneasy forming political perspectives. For Lorette, who joined the Lille-MLAC in 1978, 'it was something concrete. [. . .] All in all for me it was easier to do things'. Women with no political background preferred taking actions with tangible results, which immediately made them feel useful. In this sense, the muchpraised 'pratique' was a less costly means of entry for Claire in the Place-des-FêtesMLAC in 1978:

It matched the values I wanted to defend, political values. But at the same time it wasn't directly political. For me it's easier to get involved in social work than in politics. Also because I feel undecided, unable . . . to defend ideas, while I can defend things. I've a lot more difficulty with movements, speeches.

Accordingly, both seasoned and first-time activists who were perplexed by other feminist groups highly valued, instead, practical activities, 'not based on feminist theories' (Maryse, Aix-MLAC, later Lyon-MLAAC ${ }^{5}$ ), in their approach towards fighting for women's emancipation, as Marie (Place-des-Fêtes-MLAC) states,

I felt like I was finally doing something. To be an activist in something that wasn't a group seeking to recruit, with political ideas to defend and speeches to give and so on, but instead something that was really ours ... that really concerned me. And it corresponded to what I thought about women, that it was crucial not to let - finally to be active. I don't know how to say this. [...] A practice strongly related to the ideas we shared.

When recalling the collective identity elaborated in her group, Marie sketches a practice-led model of feminism. Indeed, over time, bodily issues bolstered the MLAC's denunciation of gender inequality without necessarily using the label 'feminist'. In other words, they 'discovered' in actuality what defending women's cause could mean. What the interviewees felt by doing was instrumental in recognizing their belonging to a collective identity. Emotional motivation is thus among the pillars of participation: more than a means of integration, it conditioned their political engagement.

Such involvement processes, 'loaded with the term experience' like in the self-help movement (Murphy, 2012: 80), demonstrate what I call an 'experiential commitment to feminism'. With their organizational settings dissenting from the usual activist culture, MLAC groups fostered skills associated with women's dispositions, their relation to caring and procreative labour, their commitment to action-oriented and everyday life politics. The anchoring in empirical knowledge and emotions therefore consecrated a gendered repertoire of action. The next section examines this repertoire and the subsequent construction of collective identities through in-depth analysis of how MLAC activists worked to shape specific emotional and physical experiences for aborting women. 


\section{Channelling emotion and care into resources for activism}

By unearthing the experiences of women seeking abortion in dissident MLACs, major dimensions of care work emerge: how care work is embedded in women's sociability, how it participates in subjectivation processes, and how it ignites knowledge production and exchange. To begin with, after 1975, women turned to dissident MLACs because the framework for lawful abortions excluded them (minors without parental authorization, foreigners, poor women ${ }^{6}$, abortions over the 10-week limit). Moreover, the simplicity of the process combined with personalized support contrasted with the guilt-inducing and cold procedures in hospitals often mentioned in the archives.

Yet, the new political context following the legalization of abortion necessarily influenced the dissident MLACs' emotional culture (Morgen, 1995). Their marginalization among feminist organizations implied what Guenther (2009) would call an emotional opportunity structure: facing multi-faceted adversity, the survival of these autonomous groups hinged upon their ability to cultivate an emotional culture that transformed users into committed constituents. Given variegated dispositions towards protest, I contend that these MLACs drew on a broad set of participants' emotions, thus going beyond the opposition between action-oriented and passive emotions (Reger, 2004: 220), since they both resolved immediate material concerns (abortion provisioning, self-help practices) and engaged in consciousness-raising (social change).

\section{Affective entanglements}

MLACs' activists organized collective welcome by facilitating weekly advisory sessions with women seeking abortion and/or contraception. They triggered discussions for the women to get to know each other and to share their similar situations. The absence of medical qualifications helped establish a balanced relationship between users and 'experts': '[the activists] were women like me, who had also already aborted, instead of people who would lecture you', Olga remembers. And yet, as these laywomen did not benefit from the presumption of competence bestowed upon physicians, the priority of creating feelings of safety for users implied the association of relational skills with evidence of technical ability.

Women planning to abort were required to consult, possibly together, a general practitioner to confirm the length of pregnancy and obtain prescriptions (antispasmodics, antiseptic, the pill). About 2 days before abortion, the 'preliminary meeting' with a team of three to five activists occurred in a private place, preferably one of the aborting women's homes. This crucial moment of their protocol aimed to personalize the support provided to women wanting abortion, while avoiding depoliticized one-on-one conversations.

Preparatory meetings were women-only spaces, in order to generate a climate of trust among aborting women, but also with the abortionists - confidence being essential to establishing any care relationship. The conviviality of food sharing and the closeness resulting from discussions about each other's lives and sexuality initiated relationships of complicity, even friendship as a woman in Lyon wrote,

Thanks to this second meeting, I am getting very comfortable with them and the feeling of trust I have proves that I am ready to live to the fullest what I have chosen. I no longer have strangers 
in front of me who will intervene on my body, but rather some friends who offer me their help and their knowledge. ${ }^{7}$

Plenty of time was dedicated to detailing the method to be used, so that the women could visualize the procedure, touch the tools and concretely comprehend the vacuum aspiration principle. The pelvic exams done during these meetings (to estimate gestational age and uterus shape) helped to remove inhibitions, thereby anticipating the next steps which implied physical exposure. Cognitive immersion in the pending procedure is now viewed by Jenny - an American woman who aborted in 1977 with the Aix-MLAC and then stayed as an activist - as a 'pre-op' moment, 'that is, learning about the female reproductive system. And about the abortion: How? What do you feel? Which tools?'. While preparing bodies, the group thus worked to create a homosocial environment, a women's circle serving as emotional support.

Abortions took place in 'a familiar place, in conditions where [women] feel respected and supported ${ }^{8}$. As physician-led MLACs worked to get abortions out of ordinary dwellings, the dissident MLACs' use of domestic spaces to perform abortions was highly significant; it meant incorporating radical action within a sphere historically constructed as feminine and apolitical.

Aborting at home was, for Jenny, the hallmark of imbuing collective control: 'it was a means of knowing each other, and making us take charge of that'. She asserts that 'from the very start', the aborting women had responsibility in this space. The dissident MLACs' protocol credited the women themselves with important skills: inasmuch as they participated, through cooking, preparing the room for abortion and welcoming the group, they were a part of the technical procedure just as much as the activists were. The promotion of domestic crafts therefore contributed to the political project to reclaim their bodies.

This setting impacted care experiences. Women who aborted and testified in the MLAC archives highlighted how domesticity diminished the act's tragic connotation: 'it doesn't look like we're going to undergo surgery'9 (18-year-old student, October 1973); and amplified the friendship ties initiated in previous stages: 'The conditions in which aspiration takes place help a lot, because you are not alone at any time. You can really feel friendship and dedication around you' (19-year-old student, June 1974). 


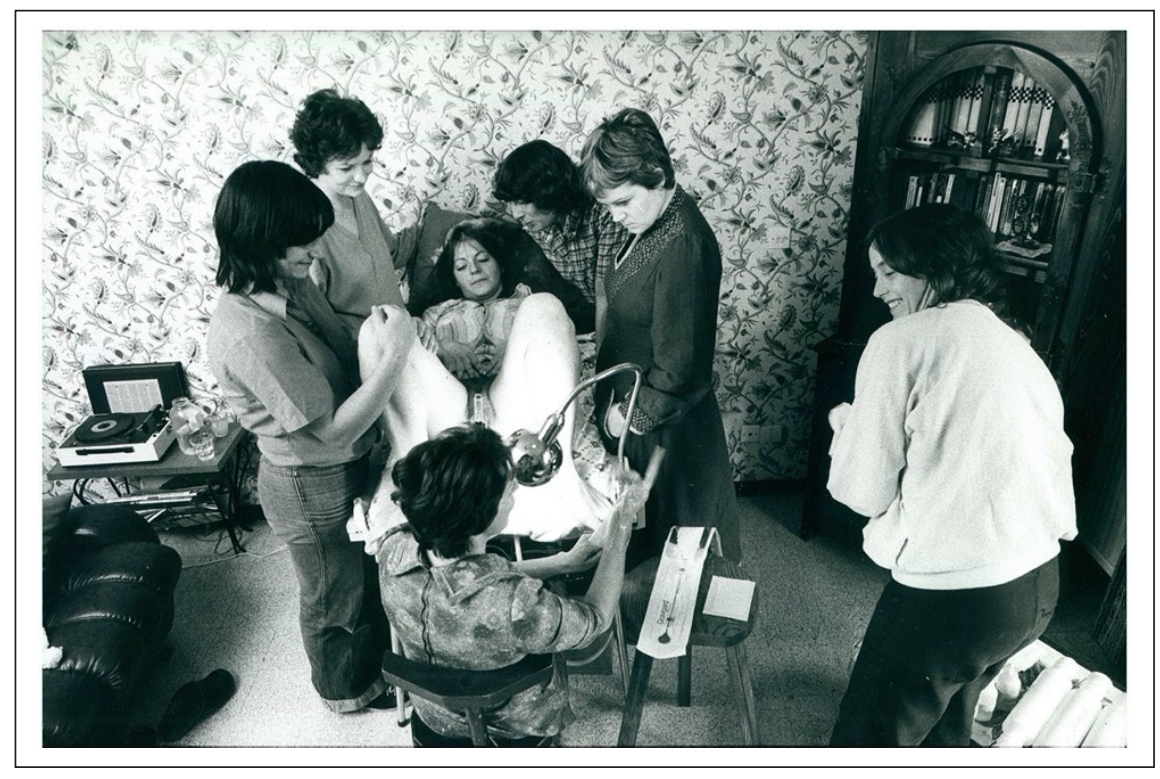

Figure 1. Aix-MLAC, five activists and a woman who aborted surrounding the one aborting. Film Regarde, elle a les yeux grand ouverts, France, 1980.

Collective attendance at abortions (see Figure 1) was designed to encourage emotional affinities, so much so that Josette describes it as a 'cocoon of emotions'. Distinct from the prevailing scenography in physician-led MLACs - where users were treated separately - the presence of several women soon to undergo or recently undergone the same procedure, who were as afraid and as uninitiated, aimed to undermine the asymmetry between abortionists and first-timers:

I was very anxious until I saw how it (abortion) was performed with a friend. After that it went easy. (26-year-old office worker, 1976)

The status granted to the aborting women as full partners in the action had a comforting effect. Focusing their attention on the aborting woman's well-being and the procedure's smooth running, the participants, soon to abort themselves, were distracted from their own anxiety. Managing the others' emotional reactions helped them deal with affective dissonance (Hercus, 1999; Taylor, 1996). The channelling of negative emotions, like distress and agitation, into empathy for others was made possible by the women's constant interactions. This supportive environment rested on diffuse attendant rules which demanded women's engagement with feelings and care work. The following account of a difficult abortion gives centrality to the comforting atmosphere, imbued with affective bonds:

Catherine settled on my right, Yasmina on my left. Opposite was Louise with a firm and reassuring air, Simone's face was full of sweetness. As for Suzanne, I won't forget her words and actions. There were also all the other women who were a little worried. It was Blandine's eyes that I clung to when Guilaine was performing the abortion and trying to extract the IUD. ${ }^{10}$ 
Among the interaction rituals underlying successful procedures, the interviewees underscore narrating abortions as they were happening, and the need for shared emotional concern. The time, words and gentleness devoted to those truly sensory encounters depict a search for alchemy. Josette recalls, 'We were being as tactful as possible. We used to say nice little words, we'd give a little caress like that (mimicking soft face caresses)'. Mireille reports women 'remaining cheek to cheek with the woman having an abortion'. These practices, between mothering and care, gave the women emotional strength to endure overwhelming sensations. When describing how the women tried to relieve pain, Dominique (Place-des-Fêtes-MLAC) expounds close relationships, as if a community of bodies had taken shape: 'We were there, sharing the pain, touching... this was a kind of hand-to-hand relationship. So that she is not alone in her pain'. Similarly, Jeanine explains that the accompanying women, including the 'operator' (holding the cannula), must make sure 'to be always in tune with the person, all the time'. Through mixed sensitive gesture and speech, the activists performed intensive emotion work. By capturing women's subjectivities throughout procedures, these exchange rituals (Taylor, 1995; Taylor and Whittier, 1995) aimed to make emotions circulate between abortionists and aborting women.

Moreover, tender relationships were credited with effectiveness both in terms of care and mutual affinities. 'Creating a climate of equality and tenderness among all those present ${ }^{\prime 11}$ is a condition formally incorporated in the Aix-MLAC's protocol: relational skills and the production of positive emotions were thus as valuable as technical dimensions. After a few months' hindsight, Odile presented their know-how through the prism of emotions: 'We never interpreted interventions at the technical level', which "was a way of respecting women. We had to be perfect and we did it with love'12. Engagement in emotional work was a basis for reciprocal emotions and recognition among women, bound by shared processes. For instance, in March 1974, a 23 -year-old nursing auxiliary did not separate her experience from that of the other woman aborting that same day: 'the aspiration went well for both of us. There was a good atmosphere'. This specific emotion culture thus instilled collective belonging between aborting women. In 1979, a 20 -year- old student even defined her abortion through emotional alliances:

Abortion ... what a word with vague and somewhat frightening content. I don't know how to name what happened this morning. In the end, what I remember are Irene's eyes, Odile's hand, Edith's smile.

Such affective economies sought to contribute to women's political awareness of control over their body.

Apart from the relief [. . .], it was a good day, lots of laughter and new friends. Also important when the facts touch you, it's an awareness of the abortion-contraception problem ...

What this 24-year-old woman wrote in 1977 illustrates the feeling rules Hochschild (1979) insists on, and the potential signal function performed by emotions: emphasizing what they gained from the group, the comments by women who aborted demonstrate that the emotional environment embodied feminist principles, instead of their discursive expression. Its consistency with feminism therefore lay in sustaining affective bonding between women. 


\section{Embodied ways of knowing}

To explain how emotions became crucial to the dissident MLACs' feminist politics, one has to understand that both abortionists and aborting women shared the feeling that this experience was a source of knowledge about their body. First, the activists kept affirming their awareness of the vulnerability caused by exposing intimate parts. Their training was profoundly embodied: they learnt by body and emotions how to pay attention to the variability of women's relationships to their bodies, and they experienced nudity in the presence of a group before undertaking abortions. Otherwise, as Louise tells me, 'how precisely do you respond to a fit of modesty of a woman who has to get on the table to have an abortion?' In Aix, they '[took] themselves as guinea pigs' to experiment with examinations (pelvic exam, IUD insertion, etc.). Such processes radically contrasted with conventional knowledge production in medicine, disconnecting the knowers' position and denying their personal entanglements with respect to investigated phenomenon. The abortionists' involvement meant using one's own body to get a better understanding (Murphy, 2012) and increasing women's control over abortions.

In addition, these MLACs systematized processes which fully incorporated women having abortion: mirrors so that women viewed what the speculum framed, pelvic exams using their own hand, descriptions of each step, speculum self-insertion, the possibility of seeing the pregnancy tissue. Attributing 'beauty' to the cervix, the activists prevented any projection of disgust and elevated women's bodies to valuable substances of concern. By attempting to heighten closeness to bodies, the challenge was to 'transform ignorance' (Tuana, 2006) and invert patriarchal representations women had unwittingly absorbed about their sex. Such statements conditioned the emotional register and the women's state of mind since they legitimized pleasant curiosity for one's own body as appropriate emotions, thereby channelling current shame and guilt into joy and fervour. Furthermore, they challenged medical control by championing abortions without general anaesthetic - GA was common practice in many abortion centres at that time - in conjunction with peer support; they affirmed the superiority of care, affective entanglements and emotional commitment over technical aspects. Indeed, the activists tested methods that became rituals to deal with pain. They employed an open-mouth, fast and jerky breathing borrowed from the method of painless childbirth, and used different kinds of touch - holding hands, caressing faces, massaging - gaze and words; the core idea was to maintain continuing interconnectedness.

Some abortion stories even tended to transmute pain:

Of course there was pain, but so many other things [. . .]: the feeling of no longer being alone facing my problem, the possibility of consciously living my abortion and understanding it at the technical level. [ . . ] Also of controlling the pain instead of living it withdrawn, sharing it with friends. [. . . At that moment we can feel this collective force so much it gives the impression that together, united, we could move mountains. ${ }^{13}$

This emotional framing intended to refute medical discourses of failure, morbidity and pain regarding abortions - still prevailing today (Lee, 2003).

Immediately following abortion was, once again, meal sharing, hence the fostering of sociality, that could have a festive quality: 
I felt a lot of warmth from all the girls [. . .]. The apple pie was delicious. (26-year-old phone interviewer, April 1977)

Despite slight anxiety at the beginning, with the attention and kindness of those present it's almost a day of celebration, especially once [the abortion] is over. (21-year-old, unemployed, September 1974)

Ending abortions with a meal epitomized the sociality of deep emotional and physical sharing (Ahmed, 2014). This stage was also conducive to experience sharing between abortionists and women who aborted, who discussed further issues related to contraception and sexuality, favouring comparisons. Engaging their personal lives and emotions was a central goal, just as activists involved their bodies in learning gestures. In this vein, in physician-led MLACs in 1973-1974, some women blamed the physicians for wilful detachment from conversations with women who had abortion on fertility control, while others accused leftist men of exempting themselves from emotional commitment, thereby recreating medical encounters. In contrast, the dissident MLACs hoped to accentuate commonalities among women and to turn aborting women into protesters.

A core recruitment tool was the suggestion that women who aborted return to one of the advisory sessions in the following weeks to give an account of their experience. By prioritizing contextualized transmission from women who aborted to aborting women whereas hospitals disregarded the exchange of knowledge between them - they endorsed alternative epistemic resources (Collins, 2000), validating knowledge generated through collective and embodied experiences. Finally, the stories of women who had an abortion sought to reassure newcomers, who could identify with those who preceded them. The abortion experience came full circle, since the objective was again the production of bonding emotions.

\section{Conclusion}

Seeking to break with the loneliness of both self-managed abortion and hospital procedures after the 1975 law, the dissident MLACs created an environment conducive to open expressiveness towards bodies that demystified clinical practices while solemnizing their empathic protocol. By inventing rituals interweaving caring and technical aspects, their approach sought to sustain not only collective work throughout the procedure, but also feminist political subjectivation - albeit tacitly. Indeed, the activists hoped the position of active knowing subject would encourage women to take control of their lives in various dimensions. The notion of experiential commitment to feminism thus aims to underscore original mechanisms of political socialization: the handling of emotions and embodied experiences. The dissident MLACs' 'practical feminism' arose from women's embodied knowledge of fertility control and procreative labour. Deploying a pattern of activism adjusted to their relational skills, their concern for concrete action and for support networks at the community level (Naples, 1998; Robnett, 1996), these groups could then appeal to women whose social backgrounds and resources did not predispose them to collective action. The emotion culture and resolution of domestic problems resonated with women's assigned roles as caregivers 
(Glenn, 2010), stemming from their position in gender, class and race power relations.

While the literature on feminism and emotions has tended to discuss gendered dispositions as barriers to women's activism, my analysis supports a broader research horizon. Taking seriously the role of feminine moral standards and ascribed identities, Celene Krauss (1996) argues the 'everyday practice of mothering' can become a resource for grassroots activism. The case of the dissident MLACs also shows that gender norms and features of sociability were precisely collective action resources for many interviewees who still claim a relationship to politics closely 'mediated by subjective experiences and interpretations' (Krauss, 1996: 248). In fact, their feelings of injustice rooted in everyday life were the driving forces of their interest in the abortion struggle, while the dissident MLACs made bodies the foundations of their emotion culture. Not only did they attempt to 're-socialize their (potential) members' (Flam, 2005: 24), but their emotional short-term microcosm, more or less purposively, drew on dominant norms of women as nurturers and carers to generate collective action. They redeemed structural constraints in women's lives as activist skills, going as far as to conceive of domestic skills as resources for their counter-expertise. Accordingly, these groups elevated a socially situated set of knowledge and dispositions, namely care, conviviality, mutual aid and the display of emotions, albeit marked as 'domestic' - a sphere that collective action usually ignores - into political skills, up to the point of making the household a legitimate space of activism. 


\section{Notes}

1. In March 1977, six of Aix-MLAC's activists were brought to trial on a charge of performing abortions and illegally practicing medicine. Following a great mobilization, the verdict was lenient: they received a suspended jail sentence of 1 or 2 months.

2. Reflecting on how the activists' Whiteness shaped their action and women's experience would introduce a new discussion, that is definitely too vast for this article.

3. For instance, Zoé aborted at the age of 12; Olga gave birth at 19 years after hiding her pregnancy.

4. Brigitte (activist in Lille-MLAC).

5. This group initiated in 1979 named itself MLAAC, the second A standing for 'accouchement' (childbirth).

6. Hospital abortions cost about 700 French francs in 1975 whereas they were free or very cheap in the MLACs.

7. Dominique's account, MLAAC Bulletin, $\mathrm{n}^{\circ} 1$, no date.

8. Flyer, 'L'avortement c'est l'affaire des femmes', 1979. Place-des-Fêtes-MLAC archives.

9. Abortion form, Aix-MLAC archives. The abortion forms' excerpts mentioned throughout this section are from the same archives.

10. Letter from Martine. MLAAC archives.

11. How we practice vacuum aspiration abortions. Press pack 'Women in trial', March 1977. AixMLAC archives.

12. Eleven-participant discussion, 12 September 1978. Private archives.

13. Témoignages, MLAAC Bulletin, $\mathrm{n}^{\circ} 1$.

\section{References}

Achin C and Naudier D (2010) Trajectoires de femmes 'ordinaires' dans les années 1970. La fabrique de la puissance d'agir féministe. Sociologie 1(1): 77-93.

Ahmed S (2014) The Cultural Politics of Emotion. Edinburgh: Edinburgh University Press.

Bateman-Novaes S (1979) La Demande d'avortement. PhD Thesis, EHESS, Paris.

Brown P, Zavestoski S, McCormick S et al. (2004) Embodied health movements: New approaches to social movements in health. Sociology of Health \& Illness 26(1): 50-80.

Coe AB and Schnabel A (2011) Emotions matter after all: How reproductive rights advocates orchestrate emotions to influence policies in Peru. Sociological Perspectives 54(4): 665-688. Collins PH (2000) Black Feminist Thought: Knowledge, Consciousness, and the Politics of Empowerment. New York: Routledge.

Ferree MM (1992) The political context of rationality: Rational choice theory and resource mobilization. In: Morris AD and McClurg Mueller C (eds) Frontiers in Social Movement Theory. New Haven, CT: Yale University Press, pp. 29-52.

Flam H (2005) Emotions' map. A research agenda. In: Flam H and King D (eds) Emotions and Social Movements. London: Routledge, pp. 19-40.

Glenn EN (2010) Forced to Care: Coercion and Caregiving in America. Cambridge, MA: Harvard University Press.

Gould DB (2002) Life during wartime: Emotions and the development of ACT UP. Mobilization 7(2): 177-200.

Guenther KM (2009) The impact of emotional opportunities on the emotion cultures of feminist organizations. Gender \& Society 23(3): 337-362.

Hercus C (1999) Identity, emotion, and feminist collective action. Gender \& Society 13(1): 34-55.

Hochschild A (1979) Emotion work, feeling rules, and social structure. American Journal of Sociology 85: 551-575.

Hochschild A (1990) Ideology and emotion management: A perspective and path for future research. In: Kemper TD (ed.) Search Agendas in the Sociology of Emotions. Albany, NY: State University of New York Press, pp. 117-142.

Jasper JM (1998) The emotions of protest: Affective and reactive emotions in and around social movements. Sociological Forum 13: 394-424. 
Kesselman A, Booth H, Rothstein V et al. (1998) Our gang of four: Friendship and women's liberation. In: DuPlessis RB and Snitow AB (eds) The Feminist Memoir Project. Voices from Women's Liberation. New York: Three Rivers Press, pp. 25-53.

Krauss C (1996) Women and toxic waste protests: Race, class and gender as resources of resistance. Qualitative Sociology 16(3): 247-262.

Lee E (2003) Abortion, Motherhood, and Mental Health. Medicalizing Reproduction in the United States and Great Britain. New York: Aldine de Gruyter.

Masclet C (2017) Sociologie des féministes des années 1970. Analyse localisée, incidences biographiques et transmission familiale d'un engagement pour la cause des femmes en France. PhD Thesis, Lausanne and Paris 8 Universities.

Morgen S (1995) 'It was the best of times, it was the worst of times': Emotional discourse in the work cultures of feminist health clinics. In: Ferree MM and Martin PY (eds) Feminist Organizations: Harvest of the New Women's Movement. Philadelphia, PA: Temple University Press, pp. 234-247.

Murphy M (2004) Immodest witnessing: The epistemology of vaginal self-examination in the U.S. feminist self-help movement. Feminist Studies 30(1): 115-147.

Murphy M (2012) Seizing the Means of Reproduction. Entanglements of Feminism, Health and Technoscience. Durham, NC: Duke University Press.

Naples N (1998) Grassroots Warriors: Activist Mothering. Community Work, and the War on Poverty. New York: Routledge.

Pavard B (2012) Si je veux, quand je veux. Contraception et avortement dans la société française (1959-1979). Rennes: PUR.

Reger J (2004) Organizational 'emotion work' through consciousness-raising: An analysis of a feminist organization. Qualitative Sociology 27(2): 205-222.

Robnett B (1996) African-American Women in the Civil Rights Movement, 1954-1965: Gender, leadership, and micromobilization. American Journal of Sociology 101(6): 1661-1693.

Ruault L (2017) Le spéculum, la canule et le miroir. Les MLAC et mobilisations de santé des femmes, entre appropriation féministe et propriété médicale de l'avortement (France, 19721984). PhD Thesis, Lille University.

Taylor V (1995) Watching for vibes: Bringing emotions into the study of feminist organizations. In: Ferree MM and Martin PY (eds) Feminist Organizations. Philadelphia, PA: Temple University Press, pp. 223-233.

Taylor V (1996) Rock-a-by-Baby: Feminism, Self-Help, and Postpartum Depression. New York: Routledge.

Taylor V (2000) Emotions and identity in women's self-help movements. In: Stryker S, Owens TJ and White RW (eds) Self, Identity, and Social Movements. Minneapolis, MN: University of Minnesota Press, pp. 271-299.

Taylor V and Rupp LJ (1993) Women's culture and lesbian feminist activism: A reconsideration of cultural feminism. Signs 19(1): 32-61.

Taylor V and Whittier N (1992) Collective identity in social movements: Lesbian feminist identity. In: Morris AD and McClurg Mueller C (eds) Frontiers in Social Movement Theory. New Haven, CT: Yale University Press, pp. 104-129.

Taylor V and Whittier N (1995) Analytical approaches to social movement culture: The culture of the women's movement. In: Johnston H. and Klandermans B. (eds) Social Movements and Culture. London: UCL Press, pp. 163-187.

Tuana N (2006) The speculum of ignorance: The women's health movement and epistemologies of ignorance. Hypatia 21(3): 1-19.

Whittier N (1995) Feminist Generations. the Persistence of the Radical Women's Movement. Philadelphia, PA: Temple University Press.

Zancarini-Fournel M (2003) Histoire(s) du MLAC (1973-1975). Clio 18: 241-252. 